Observatório de Inovação do Turismo

Revista Acadêmica

ISSN 1980-6965

\title{
Festejo junino em Miguel Calmon-Bahia: estudo do potencial turístico-cultural para o município
}

\author{
June festivities in Miguel Calmon-Bahia: study of cultural \\ and touristic potential of the city
}

Fabiana Nery dos Santos Ana Paula Carvalho Cruz Feitosa

\section{Resumo}

No presente artigo, o principal objetivo é analisar o potencial do São João Calça Curta como produto turístico-cultural para o município de Miguel Calmon-Bahia. Desse modo, buscou-se, especificamente, refletir sobre as manifestações culturais populares como atrativos turísticos em alguns destinos, apresentar as características artístico-culturais do festejo junino São João Calça Curta e levantar dados sobre o produto turístico do município e seu potencial para o turismo. Quanto ao procedimento metodológico, fizeram-se entrevistas semiestruturadas com os organizadores do festejo, observou-se in loco no período em que ocorreu o evento em 2014 e reviu-se a bibliografia acerca do tema. Na pesquisa, revelou-se que o São João Calça Curta - objeto de estudo deste trabalho - tem potencial de produto turístico-cultural para o município, por causa da variedade de atrativos que apresenta, como a inserção da comunidade local na realização da festa.

Palavras-chave: manifestações culturais, turismo, produto turístico-cultural, festas juninas

Artigo recebido em 05 de Novembro de 2014 e aceito em 09 de Dezembro de 2014. 


\section{Abstract:}

This article aims to analyze the potential of São João Calça Curta (Short Pants) as a cultural tourism product for the Miguel Calmon city in Bahia. This way, it was sought to specifically reflect on the popular cultural events as tourist attractions for some destinations, presenting artistic and cultural features of the Junin celebration "São João Calça Curta" and to collect data about the tourism product of the city and its potentiality tourism. The methodological procedure: partially structured interviews with people who administer the festivities, watching during the period in which the event had happened in 2014 and a literature review on the topic. The research revealed that the incident of Miguel Calmon shows potentiality for tourism and for the practice of the "São João Calça Curta", study object of this work has potential as a cultural tourism product for the city, that in recurrence to the variety of attractions it contains and among other factors, by the insertion of the local community in realizing the party.

Key words: cultural events, tourism, cultural tourism product, june festivals

\section{Introdução}

O turismo é uma atividade que vem crescendo acentuadamente no decurso do tempo. Logo, são milhares de turistas que se deslocam de suas regiões e vão a outros destinos em busca de novas oportunidades, conhecimento do outro e vivência de culturas distintas, gerando para o destino local relevantes benefícios, ao levar-se em consideração os efeitos multiplicadores nos aspectos sociais, culturais, econômicos, ambientais e políticos (BRASIL, 2010).

Tal precedência dá-se pela necessidade humana de festejos, tradições, fuga da rotina e pela representação histórica que transcorrem em fatos que garantem a qualidade de vida e a manutenção das relações sociais. Dessa forma, o turismo surge como principal meio de suprir expectativas e anseios do indivíduo que, atualmente, se encontra cada vez mais exigente e anseia por 
itinerários e segmentos novos. Além disso, o evento cultural, como fomentadores da cultura, insere os turistas no lugar visitado e proporciona-lhes a obtenção de maior ciência dele (FOSCARINI, 2009).

As celebrações têm grande potencial de atração de turistas para localidades em que não há atrativo turístico formatado; mas é preciso organização sem a qual não é possível captá-los e fidelizá--los. Nesse contexto, no município de Miguel Calmon, localizado ao norte da Chapada Diamantina, desde 1997, realiza-se o festejo junino São João Calça Curta - de origem popular e religiosa - que é a expressão cultural do município, mantém-se respaldado pela tradição e inovação, incentivado por entidades, pela população local e pelo público que o visita.

Nessa perspectiva, a problemática deste estudo ganha importância quando se reconhece que há uma tendência no mercado turístico de valorização e apropriação das manifestações culturais populares para o desenvolvimento turístico dos destinos. Dessa maneira, é imprescindível estudar o potencial das manifestações e, em seguida, a formatação para a atividade turística de alguns destinos ainda não divulgados. Existem, por exemplo, festejos que são atrativos já consolidados e têm o poder de atrair grande fluxo de demanda, como o Maior São João do Mundo em Campina Grande e o Carnaval em Salvador e no Rio de Janeiro.

Com foco em Miguel Calmon e suas manifestações, pretende-se, por meio da problemática, averiguar se é possível formatar o festejo junino, São João Calça Curta, como um produto turístico cultural para o destino. Como objetivo geral, buscou-se analisar o potencial do São João Calça Curta no município de Miguel Calmon como produto turístico-cultural. E, como objetivos específicos, enumeraram-se as seguintes pretensões: refletir sobre as manifestações culturais populares como atrativos turísticos para alguns destinos; apresentar as características artístico-culturais do São João Calça Curta como manifestação 
cultural; levantar dados sobre o produto turístico do município e seu potencial para o crescimento do turismo.

Para o desenvolvimento da pesquisa, realizaram-se duas etapas. A primeira foi bibliográfica em que se buscaram dados secundários, como livros, dissertações, monografias e artigos relacionados com o tema. A segunda, para a obtenção de dados primários, foi destinada a pesquisas de campo entre os meses de janeiro, fevereiro e junho de 2014. Para isso, realizaram-se pesquisas de campo para identificar a quantidade de equipamentos turísticos contidos na cidade, fundamentais para atender à demanda durante o evento. Posteriormente, houve observação direta no local para averiguar a qualidade da infraestrutura e as condições atuais das vias que dão acesso ao município. Em seguida, fizeram-se verificações e análises dos atrativos turísticos presentes na localidade, em especial, o São João Calça Curta, para constatar se o município apresenta potencial turístico.

\section{O turismo e suas segmentações}

Abordar o turismo e suas segmentações requer uma análise sucinta de todos os meios que o compõem. Todavia é evidente a importância que a segmentação traz para o desenvolvimento turístico em seus diversos setores (NETTO; ANSARAH, 2009).

A necessidade de segmentar o mercado turístico surge em virtude de empresas e entidades desejarem atingir, de maneira eficaz e confiável, a demanda e sua potencialidade a fim de contribuir para o desenvolvimento turístico das localidades inseridas. Mas, para isso, utilizam-se meios para abarcar todo público que se dispõe a consumir bens e serviços encontrados nos destinos (PANOSSO, ANSARAH, 2009). 
Como ferramenta, o planejador de turismo utiliza-se das estratégias de marketing para alcançar potenciais consumidores, tendo em vista critérios voltados para as relações entre demanda e oferta. É de grande valia essa perspectiva, pois, ao conhecer-se o mercado que se pretende atingir, torna-se mais fácil o direcionamento da oferta e possibilita-se um maior retorno para os agentes envolvidos nos investimentos realizados (LOHMANN; NETTO, 2008). Quanto ao mercado turístico, Bissoli (1999, p.170) afirma:

[...] se baseiam no eterno confronto entre a demanda, os consumidores, no caso, os turistas, os produtores ou vendedores de produtos e serviços turísticos, no caso, as empresas hoteleiras, as agências de viagem, as empresas organizadoras de eventos, as empresas que atuam na área de entretenimento, de transportes, gastronomia etc.

Tal fator é o resultado da análise entre uma demanda cada vez mais exigente e um mercado que se encontra saturado, mas que se apropria de turistas para gerar benefícios fundamentais para o crescimento e a propagação.

Brasil (2010. p. 61) esclarece o que é segmentar a atividade turística:

[...] uma forma de organizar o turismo para fins de planejamento, gestão e mercado. Os segmentos turísticos podem ser estabelecidos a partir dos elementos de identidade da oferta e também das características e variáveis da demanda.

A ressalva acima é fruto de extensa procura pela especialização dada pelo mercado turístico e também por causa dos turistas ou consumidores que estão colocando nessa atividade alguns de seus anseios e necessidades de fuga da vida cotidiana. Daí a origem da imensa busca pela segmentação no turismo. Entre os variados segmentos que o compõe, pode-se citar o turismo de sol e praia, o de base comunitária, o rural, o de evento, o cultural. Já que a demanda está cada vez mais exigente, segmentar a atividade turística é garantir variadas opções de atrativos (CERQUEIRA, 2008). 
Diante disso, pode-se observar que a segmentação tornou-se a grande saída para as empresas atuantes no mercado, seja ou não na área do turismo, e, para os consumidores, a possibilidade de proporcionar-Ihes variados tipos de oferta e serviços, capazes de suprir ou atender a seus desejos e necessidades.

\section{Turismo cultural}

O turismo cultural pode ser considerado como um dos principais segmentos e, de modo geral, está associado a outras atividades turísticas. Pode ainda ser definido como uma atividade de lazer num parâmetro educacional, pois contribui para a consciência do visitante e sua apreciação da cultura local em todos os elementos - histórico, artístico, social e político (OLIVEIRA, 2010).

Averígua-se que esse segmento tem sido atualmente um dos elementos fundamentais para o desenvolvimento de uma região, ao contribuir para promover o envolvimento das comunidades com sua história, seus atrativos culturais e sua memória social (CRUZ, 2008).

Dias (2005, p. 36), por sua vez, assim define turismo cultural:

[...] uma segmentação do mercado turístico que incorpora uma variedade de formas culturais, em que se incluem museus, galerias, eventos culturais, festivais festas, arquitetura, sítios históricos, apresentações artísticas ou outras, que, identificadas com uma cultura em particular, fazem parte de um conjunto que identifica uma comunidade e que atraem os visitantes interessados em conhecer características singulares de outros povos.

Beni (2003) ressalta que esse segmento turístico se relaciona com a influência de turistas a núcleos que oferecem, como produto essencial, o legado histórico do homem em distintas épocas, representado com base no patrimônio e no acervo cultural encontrado nas ruínas, nos monumentos, nos museus e nas obras de arte. Destarte, compreende-se que o turismo cultural, em sua interface, está voltado para modificações e ações humanas em detrimento de tempo e 
espaço com o intuito de assegurar à sociedade vindoura a representatividade da cultura local. Goeldner, Ritchie e Mcintosh (2002, p.151) asseveram:

[...] turismo cultural cobre todos os aspectos através dos quais as pessoas aprendem sobre as formas de vida e pensamento umas das outras. O turismo, assim, é um importante meio para promover relações culturais e cooperação intercultural. Por outro lado, o desenvolvimento de fatores culturais dentro de uma nação é um meio de aprimorar recursos para atrair visitantes.

Nessa abordagem, englobam-se os enfoques relacionados com os aspectos culturais e aponta-se a motivação de um turista para a cultura, ou seja, o que o faz viajar vários quilômetros está em conhecer o outro, participar do cotidiano e da história de um novo grupo. Hoje, é notório o aumento da demanda por tais atrativos, deixando à margem o segmento de sol e praia e agregando aos itinerários a visita a museus, sítios arqueológicos, entre outros.

Sobre o turismo cultural, esclarece Brasil (2006, p.15):

compreende as atividades turísticas relacionadas com a vivência do conjunto de elementos significativos do patrimônio histórico e cultural e dos eventos culturais, valorizando e promovendo os bens materiais e imateriais da cultura.

Assim, pelo turismo, tem-se a particularidade de expor a diversidade por meio da afirmação da identidade, com valores e características locais, e, ao mesmo tempo, mostra--se ao visitante que sua cultura não é única, possibilitando que perceba os valores relativos da sua em detrimento de outra (MURTA, 2002).

Lima (2001) lembra que o turismo, no decurso dos anos, vem buscando legitimidade e, nessa perspectiva, utiliza a cultura como um instrumento de validação. Hoje em dia, a cultura funciona como um aporte para a motivação e o consumo dos turistas que vêm aos destinos para conhecer e vivenciar a tradição de outros grupos. 
Para Kotler (1996), a cultura é o principal fator determinante dos anseios das pessoas, pois compreende os valores básicos, as percepções, os desejos e os comportamentos que um indivíduo aprende de forma contínua em uma sociedade.

No Ministério do Turismo (2011), abordam-se, no Caderno de Segmentação do Turismo, os benefícios proporcionados por esse segmento de turismo, destacando-se a valorização da identidade cultural, o resgate da cultura e o intercâmbio cultural proporcionado. Também se reconhece a força geradora de postos de trabalho, emprego e renda que o turismo cultural impulsiona, dinamizando o setor de negócios e a economia.

A cultura pode motivar o turista a conhecer cidades ou regiões, a história de determinado povo e suas tradições, bem como a participar dos eventos relacionados com manifestações culturais e religiosas. Assevera Barreto:

O turismo cultural, no seu sentido mais amplo, seria aquele que não tem como atrativo principal um recurso natural. As coisas feitas pelo homem constituem a oferta cultural, portanto turismo cultural será aquele que tem como objetivo conhecer os bens materiais e imateriais produzidos pelo homem (2003, p. 21).

Portanto, pode-se afirmar que o turismo cultural é um dos segmentos turísticos precursor da integração entre demanda e população anfitriã, desencadeando, pelo contato, a troca de conhecimentos e experiências. Investir, portanto, nesse setor é garantir a expansão cultural entre diversas regiões do mundo e seu fortalecimento para as gerações vindouras.

\section{Manifestações culturais como atrativo turístico}

As manifestações culturais são marcadas pela representação cultural de um povo. São elas também responsáveis pela divulgação e formatação dos 
destinos inseridos. Suas diversificações atraem inúmeras pessoas em busca do conhecimento e da representação cultural da população local.

Nessa perspectiva, é imprescindível defini-las para compreender as características presentes nas diversas facetas. Afirma Carvalho (2011, p. 64):

As manifestações culturais estão no centro do espaço ocupado hoje pelos estudos folkcomunicacionais. A partir deste diagnóstico inicial, as mesmas podem ser entendidas como formas de expressão da cultura de um povo constituindo movimento de determinada cultura, em época e lugar específicos.

Atrelado a isso, elas também têm a capacidade de fomentar o turismo nos destinos ainda não formatados, por meio do despertar para a vivência de culturas distintas. E, quando presentes em uma determinada localidade, contribuem para o aumento do fluxo de turistas e para a divulgação da cultura anfitriã, por meio de danças, músicas e afins.

Na visão de Bosi (1999), as manifestações culturais são expressões de grupos específicos da cultura. Distingue-se da cultura oficial e encontra-se dispersa pelo território nacional. Desse modo, estão relacionadas com as vivências de um grupo específico. Elas recordam, no presente, as práticas que se desenrolaram com o passar do tempo, que não foram esquecidas pela comunidade e, logo após, são traduzidas em atrativos turísticos, contribuindo para o desenvolvimento local por meio da atribuição de valores econômicos e sociais nelas inseridos.

Pelo turismo, apropria-se dos espaços com valores culturais para contribuir de forma direta ou indireta na divulgação e formatação de um novo produto para certas localidades. E, por meio de divulgações via meios de comunicações e especificamente das estratégias de marketing, torna-se cada vez mais ampla a propagação turística dos destinos ainda não fomentados e, por conseguinte, ocorre a valorização das manifestações culturais ali encontradas (KOTLER,1996). 
Sobre atrativo turístico, Cerro (1993, p.29) afirma ser o potencial a ser explorado em função da atividade turística, tornando-se, adiante, novo recurso. Ele ainda explicita sua ideia da seguinte forma:

Pode ser compreendido como todo elemento natural, toda atividade humana ou todo produto antropológico que pode motivar um deslocamento, cuja movimentação básica seja a curiosidade ou a possibilidade de realizar uma atividade física ou intelectual. Em outras palavras, atividade turística unicamente tem lugar somente se existem atrações que motivem certa quantidade de pessoas a abandonar seu domicílio habitual e permanecer um tempo fora do mesmo; estas atrações se denominam Recursos ou Atrativos Turísticos.

Com base nisso, é viável assegurar que as manifestações culturais são atrativos turísticos; isso se dá pela capacidade que têm de atrair diversos visitantes às localidades a fim de experimentar e vivenciar uma nova cultura, além de apreciar ritos e danças capazes de expressar o modo de viver de um determinado grupo e repassar suas diversidades culturais.

\section{Turismo de eventos}

As comemorações são frequentes na sociedade moderna e tornam-se parte integrante da cultura mundial. Essas modalidades são capazes de contribuir para a integração de diversos agentes ao planejar-se e desenvolver-se a atividade (NETTO, 2009).

Além disso, representam para o turismo uma significante forma de composição do produto turístico, pois conseguem atender a exigências do indivíduo que busca o mercado de lazer, entretenimento, descanso e outras motivações. Na visão de Netto (2009, p. 30), observa-se:

Os eventos são atividades de entretenimento, com grande valor social, cultural e, sobretudo, histórico. Suas atividades constituem um verdadeiro mix de marketing, entretenimento, lazer, artes e negócios. Tal a sua importância no contexto social, cultural econômico e político da cidade e região e, em alguns casos até mesmo do país, podemos denominá-los de agentes do patrimônio históricocultural. 
Outrossim, segundo Matias (2000), um evento representa um grande estímulo para a economia de um município, uma vez que envolve grande movimentação nos mais diversos setores da economia, ocasionando um aumento geral na arrecadação das receitas, em números de empregos (diretos e indiretos), além de criar novas oportunidades para a população local, redistribuindo rendas individual, local e regional.

Durante a realização dele, ocorrem significantes interesses sociais e econômicos, perceptíveis quando se pretende extrair o máximo de lucro e resultados nas atividades desenvolvidas, trazendo, em decorrência, benefícios para os locais-sede das realizações (CANTON apud PANOSSO; ANSARAH, 2009). Possibilita, também, ao turista o despertar de novas motivações.

Atualmente, há diversas tipologias de eventos voltados especificamente para o turismo com grande potencial de atrair turistas. Os eventos culturais são exemplos dessa tendência que tem como principais atrativos manifestações, festas populares, danças, músicas, e outros com características essenciais para fazer com que aconteçam visitas às regiões.

\section{Eventos culturais: festividades juninas no Brasil}

Os eventos culturais têm despertado o desejo de visitar localidades com atrativos para conhecê-los e experimentá-los. Martin esclarece (2003, p.40):

Estes eventos culturais não são mais do que um conjunto de atividades concentrado num curto período de tempo, com um programa predefinido. De múltiplas temáticas e dimensões, o seu denominador comum reside no seu carácter diferenciado e único relativamente à oferta turística permanente, o que os eleva acima do comum/quotidiano.

Pode-se afirmar, portanto, que os festejos culturais resultam da mistura de distintas culturas provenientes de várias etnias que participam da construção 
cultural de determinada cidade ou região e que contribuem, no decurso do tempo, para a propagação turístico-cultural (RIPOLLY, 2003).

As atividades culturais têm o potencial de captar a atenção dos turistas, estimulando a repetição de visitas aos destinos. Isso é dado por meio da interação e vivência dos turistas com a história e a cultura da comunidade, do envolvimento nas manifestações culturais e das experiências adquiridas de forma natural. Para a população anfitriã, os eventos tornam--se uma alternativa de lazer, possibilitam e incentivam a troca cultural entre residentes e visitantes, além de aumentar a estima da comunidade, que passa a enxergar o patrimônio cultural como parte de sua riqueza (GOMES, 2009).

No Brasil, há significante procura por festejos culturais, especificamente, os que ocorrem no mês de junho, em razão da religiosidade, do interesse cultural e da identidade presentes nos eventos. Tal busca é o reflexo da variedade cultural existente nas regiões brasileiras cujos potenciais são importantes para atrair visitantes que vêm aos destinos à procura de novas experiências e lazer. Um exemplo disso é o festejo que ocorre em Campina Grande - O Maior São João do mundo - que atrai, todos os anos, centenas de turistas àquele destino. Sua importância baseia-se na diversidade, qualidade, quantidade e originalidade das atrações artísticas, na representatividade cultural e também nos dados estatísticos sobre contribuição econômica, investimentos do setor público e do privado, interesse da mídia, fluxo turístico e, em especial, participação da população local, tornando-o, assim, um dos maiores eventos culturais do Brasil (NÓBREGA, 2012).

\section{Procedimentos metodológicos}

O objetivo que se pretende alcançar com este trabalho resulta de apreciações teórica, exploratória, descritiva e qualitativa, aplicadas aos 
segmentos do turismo - em especial ao turismo cultural —, seguidas da análise do objeto de estudo da pesquisa que é o potencial do São João Calça Curta como produto turístico cultural para o munícipio de Miguel Calmon-Bahia. Vale lembrar Andrade (1999, p. 17) que, assim, explicita: “[...] os fatos são observados, analisados, classificados e interpretados, sem que o pesquisador interfira sobre eles".

E mais: a pesquisa é descritiva, no sentido em que se apresentam características da cidade e do festejo em questão; explicativa, uma vez que se busca esclarecer quais os fatores condicionantes do São João Calça Curta como potencialidade e/ou atrativo turístico para a localidade; e qualitativa pelo fato de que se observa a relevância do festejo para a população e para os visitantes.

É importante destacar a valia da bibliografia secundária, que, como ressaltam Lakatos e Marconi (1991, 2005), "abrange toda bibliografia já tornada pública em relação ao tema de estudo, desde publicações avulsas, boletins, jornais, revistas, livros, pesquisas, monografias, teses, material cartográfico etc." Assim, partiu-se do levantamento e revisão da literatura para a elaboração conceitual e definição do fenômeno, Além disso, fez-se pesquisa de campo por meio de entrevistas semiestruturadas com o prefeito de Miguel Calmon e o secretário municipal de Cultura e Esportes, responsáveis pela realização do São João na cidade e também com alguns moradores, para saber qual a contribuição que o referido festejo Ihes proporciona.

Na observação in loco, as variáveis são, segundo Tiboni (2003, p.15), "características que podem ser observadas (ou medidas) em cada elemento da população, ou, ainda, é um conjunto de resultados possíveis de um fenômeno", ou seja, são pontos importantes a serem analisados, capazes de responder a um determinado tipo de questionamento.

Assim, para melhor compreender o tema abordado, buscou-se apresentar três variáveis - participação da comunidade; equipamentos turísticos; 
representações culturais e atrativos turísticos - que serviram de objeto de análise.

\subsection{Análise da pesquisa}

Essa análise se deu por meio de pesquisa de campo, análise in loco da festa em 2014, registro fotográfico e entrevistas.

\subsubsection{Comunidade}

A participação da população local é de suma importância, pois é, por meio dela, que se conhece mais do que ninguém os aspectos históricos, culturais e políticos das regiões analisadas. Dallari (1993, p. 32) ressalta:

[...] Sempre que um grupo de pessoas se organiza e se dispõe a trabalhar em conjunto por um objetivo, algum resultado é conseguido, e sempre o grupo consegue mais do que qualquer um de seus integrantes obteria se agisse isoladamente. E mesmo que se consiga relativamente pouco, em vista do objetivo almejado, essas pessoas adquirem um preparo e obtêm conhecimentos que serão úteis em outro empreendimento.

Na pesquisa de campo, observou-se que o São João Calça Curta do município de Miguel Calmon surgiu da iniciativa da comunidade local, que se reunia em grupo nos bairros e nas casas e realizava o festejo, representando-o com competições de quadrilhas, fogueiras etc. Ele trazia consigo a realidade, identidade e tradição do povo (SOUZA, 2013).

Atualmente, houve alterações nesse cenário, já que o festejo ganhou amplitude e passou a ser realizado em praça pública, mas os residentes continuam participando, especialmente, da oferta gastronômica durante o São João e também das apresentações de quadrilhas e outras manifestações. Quanto às quadrilhas, são reconhecidas como criações representativas do São João Calça Curta e dividem-se em dois tipos: as tradicionais, também chamadas de caipiras, formadas por alunos das escolas do município; e as reconstruídas, compostas de moradores dos bairros. Ambas, organizadas em coletividades, são motivadas pela competitividade nos festivais realizados no transcorrer de cada ano e em diferentes localidades. Contudo para os quadrilheiros calmonenses a disputa 
mais acirrada realiza-se na programação da festa e alimenta-se há anos entre os grupos e seus respectivos bairros, o que leva os componentes a dedicarem-se ao planejamento, à organização, aos ensaios e à apresentação.

Figura 1. Quadrilha realizada por alunos das escolas do município (2014)
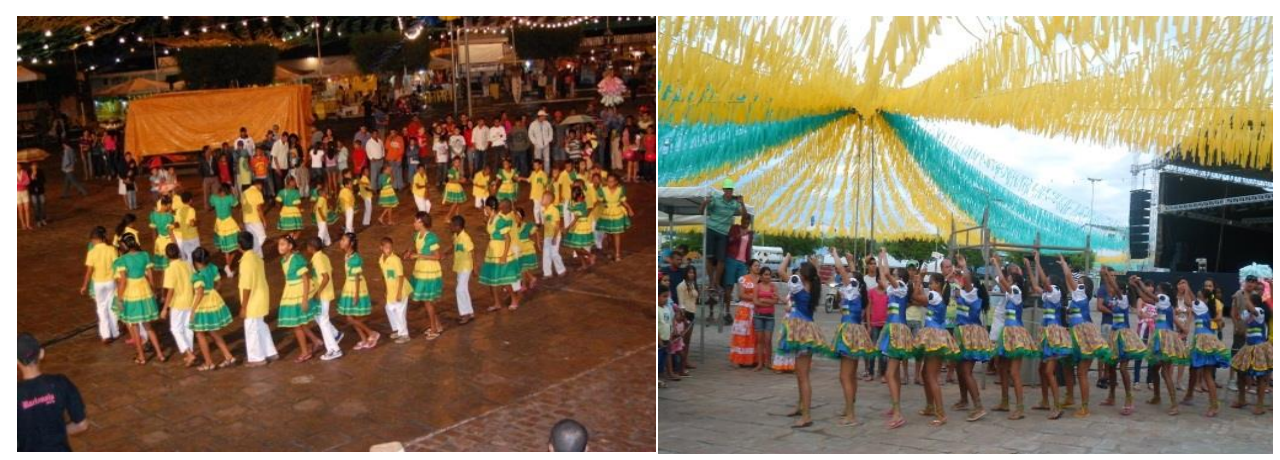

Fotógrafo: Fabiana Nery, pesquisa de campo, 2014.

Além das quadrilhas, há enorme oferta e consumo de alimentos e bebidas em diferentes lugares de realização do evento. A gastronomia para a comunidade local é um dos principais vetores econômicos e exemplo das interfaces culturais da festa, pois reforça a tradição e a identidade do homem do campo e agrega valores aos envolvidos.

Como visto durante o São João Calça Curta em 2014, a comunidade local utiliza os dotes culinários para representar a gastronomia local e decora as barracas a caráter, reforçando o verdadeiro sentido de festejar o São João no município.

Oliveira (2002) descreve que o desenvolvimento social pode ser considerado componente participativo da cidadania, mesmo no capitalismo desregulado e em tempos de globalização. Assim, os grupos que participam do São João Calça Curta em Miguel Calmon transpõem as barreiras da modernidade e inserem-se na perspectiva de buscar, na essência da cultura calmonense, formas de interpretação, por meio de músicas e danças, para expressar o passado e o presente mediante símbolos impregnados no espaço. 
Figura 2. Barracas de comidas típicas, comunidade local (2014)

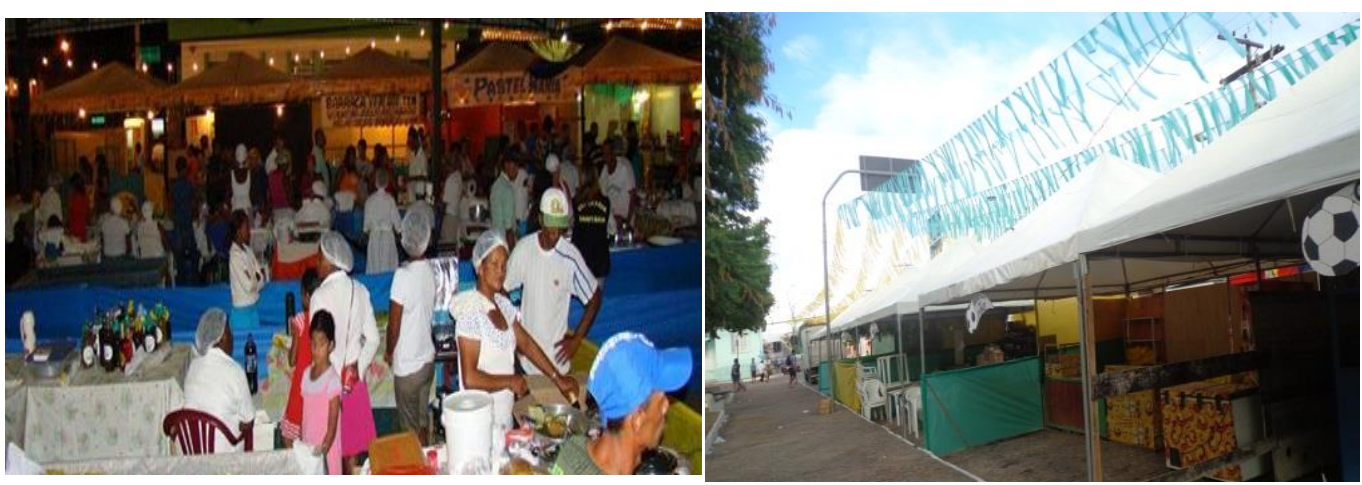

Fotógrafa: Fabiana Nery, pesquisa de campo, 2014.

Durante a observação, notou-se que houve uma grande concentração de barracas ao entorno do espaço do evento, garantindo o aumento da venda dos produtos ofertados e gerando maior rentabilidade para os envolvidos. Assim, pode-se considerar que o festejo, além de reforçar a cultura local, gera benefícios financeiros para os participantes. Com isso, pode-se afirmar que a inserção da população durante os festejos proporcionou o desenvolvimento dos capitais sociocultural e histórico do lugar. Além disso, os grupos diretamente envolvidos (idosos, adultos, jovens e crianças), sem distinção etária, sentem-se gratificados, o que pode ser considerado um fator positivo, pois aumenta o sentimento de pertencimento da comunidade.

\subsubsection{Equipamentos turísticos}

A atividade turística é fundamental para desenvolvimentos econômicosocial e histórico dos destinos inseridos. Mas, para que haja o aumento da demanda aos lugares, faz-se necessário um conjunto de equipamentos que visem ao acesso rápido e seguro.

A infraestrutura e a superestrutura podem ser consideradas como formas de compor alternativas de destinações (BENI, 2003). De acordo com Cooper (2001), elas representam todas as formas de construção em um ambiente urbano e contribuem na destinação turística, principalmente na forma de 
transporte (estradas, ferrovias, aeroportos, estacionamentos), serviços de utilidade pública (eletricidade, água e comunicações) e outros (saúde e segurança) que normalmente são compartilhados por residentes e visitantes. Barros apud Silva (2008, p. 7) lembra:

Para que haja demanda, é necessário que a localidade esteja preparada para oferecer aos visitantes mais do que atrativos. É preciso oferecer condições para que o turista permaneça pelo tempo escolhido e usufrua de uma boa infraestrutura, com serviços de qualidade.

Assim, durante a pesquisa de campo, pôde-se constatar que o município de Miguel Calmon dispõe dos serviços de saneamento básico, limpeza pública, rede elétrica, água, quatro agências bancárias (Banco do Brasil, SICOB, Caixa Econômica e Banco do Nordeste), uma delegacia, pousadas, restaurantes, transportes particulares/coletivos e escolar, um hospital, vários postos de saúde, várias clínicas particulares, três postos de combustíveis, um terminal rodoviário, entre outros equipamentos essenciais para atender aos visitantes durante o São João.

No São João Calça Curta, há um aumento considerável de imóveis disponíveis para aluguel. Tal fator é dado pelo intenso fluxo de pessoas ao destino por causa da festa e pela falta de reservas disponíveis em hotéis e pousadas do município. Muitos turistas preferem esse tipo de serviço, pois thes garante a estadia por mais tempo no destino o que lhes permite desfrutar dos atrativos ali ofertados (PREFEITURA DE MIGUEL CALMON, 2014).

Como equipamento de caráter público para o evento, há uma alteração no espaço que sedia a festa e inserem-se, como suportes para a população e visitantes, barracas, banheiros químicos, palco para a apresentação dos artistas, local de primeiros socorros, placas informativas, entre outros. Vale acrescentar que esses equipamentos são essenciais para a realização do evento e a prestação de serviços qualitativos. 
Figura 3. Tenda da comissão e preparação do palco (2014)

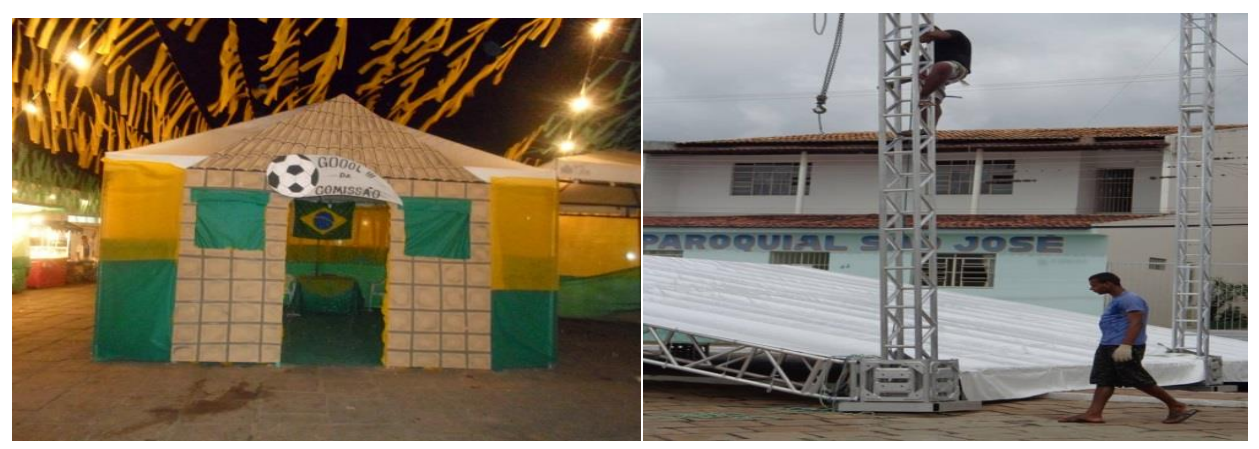

Fotógrafa: Fabiana Nery, pesquisa de campo, 2014.

Entende-se, ainda, que tais equipamentos são imprescindíveis para o município, uma vez que, com eles, o evento ganha maior visibilidade e garante a permanência dos turistas. Vale lembrar que a falta deles implicaria cancelamento do festejo e fuga dos visitantes para outras localidades.

\subsubsection{Representações culturais e atrativos turísticos}

A representação cultural é fator de extrema relevância para qualquer destino, pois tem a capacidade de motivar indivíduos a deslocarem-se de suas regiões a outras, no intuito de participar e conhecer o modo de vida da comunidade local. Quanto aos atrativos, assim define Cerro (1993, p. 30):

Todo elemento natural, toda atividade humana ou todo produto antropológico que pode motivar um deslocamento, cuja movimentação básica seja a curiosidade ou a possibilidade de realizar uma atividade física ou intelectual. Em outras palavras, atividade turística unicamente tem lugar somente se existem atrações que motivem certa quantidade de pessoas a abandonar seu domicílio habitual e permanecer um tempo fora do mesmo; estas atrações se denominam Recursos ou Atrativos Turísticos.

Nessa perspectiva, o São João Calça Curta do município de Miguel Calmon agrega, em sua realização, as diversidades de atrativos capazes de atrair e motivar pessoas a visitá--lo em todas as edições. Além disso, nota-se a presença 
de outros elementos culturais na ornamentação do espaço que sedia o evento, baseados na vida do homem do campo.

Figura 4. Ornamentação do espaço do evento (2013 e 2014)

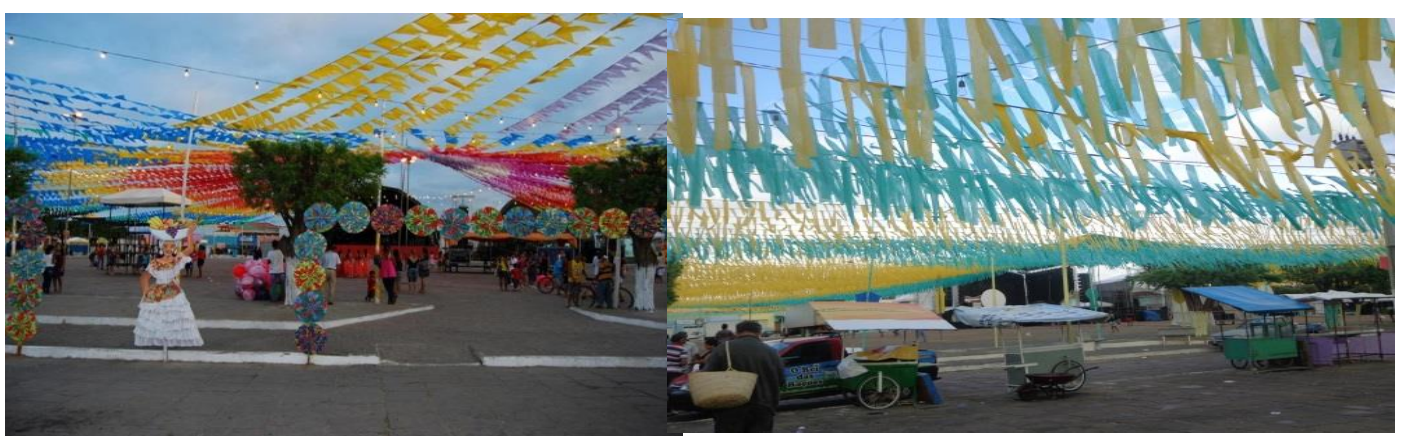

Fotógrafa: Fabiana Nery, pesquisa de campo, 2014.

Na figura acima, observa-se que, na ornamentação do espaço, onde acontece o festejo São João Calça Curta, trata-se da representatividade da comunidade local e seu envolvimento na realização do evento, reforçando-se, com isso, a tradição popular. Quanto aos usos tradicionais e populares, assim os considera Beni (2004, p. 309):

Todas as práticas culturais que são tidas como específicas de cada lugar ou região que as integram, ou ainda idênticas em nível nacional como: atividades cotidianas e festivas de ordem sacra ou profana, de caráter popular e folclórico, consideradas objeto de apreciação e/ou participação turística.

Dessa forma, o festejo calmonense e sua tradição despertam a necessidade da integração entre o homem do campo e o da cidade, pela importância para o conhecimento e a valorização de culturas. A representação cultural também é demonstrada no slogan, em que se torna visível a presença da imagem do caipira, uma vez que retrata o indivíduo do campo e também o contexto histórico do festejo junino. 
Figura 5. Slogan do São João Calça Curta (2013 e 2014)
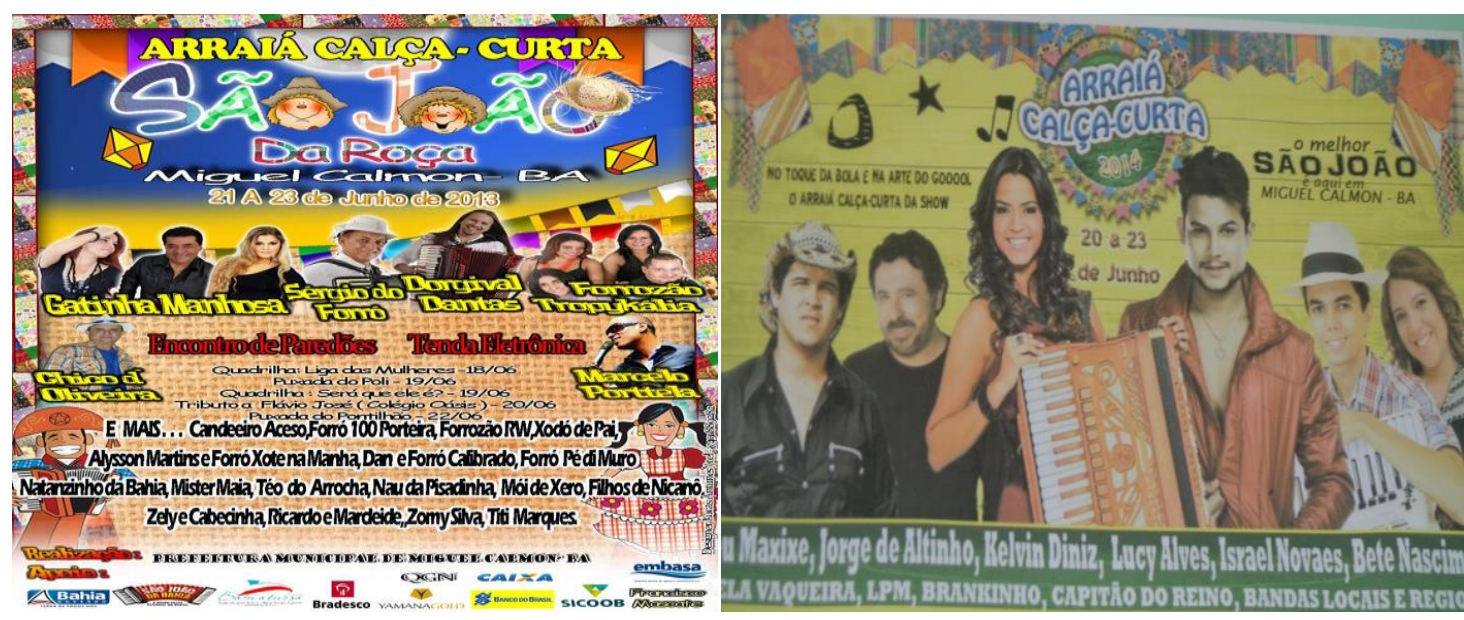

Fotógrafa: Fabiana Nery, pesquisa de campo, 2014.

Durante a realização do São João Calça Curta, predomina a apresentação de artistas que cantam os ritmos do forró. Ressalte-se que a maioria das contratações é feita pela Prefeitura com a parceria de outros organizadores, e os critérios baseiam-se em trazer cantores de renome nacional capazes de atrair grande fluxo de pessoas. Isso foi possível de ser identificado durante o festejo, em junho de 2014, quando a praça Lauro de Freitas foi tomada por inúmeras pessoas que vieram de várias localidades para "curtir" o som de Lucy Alves e Israel Novaes, e de outros grupos.

Figura 6. São João Calça Curta (2014)

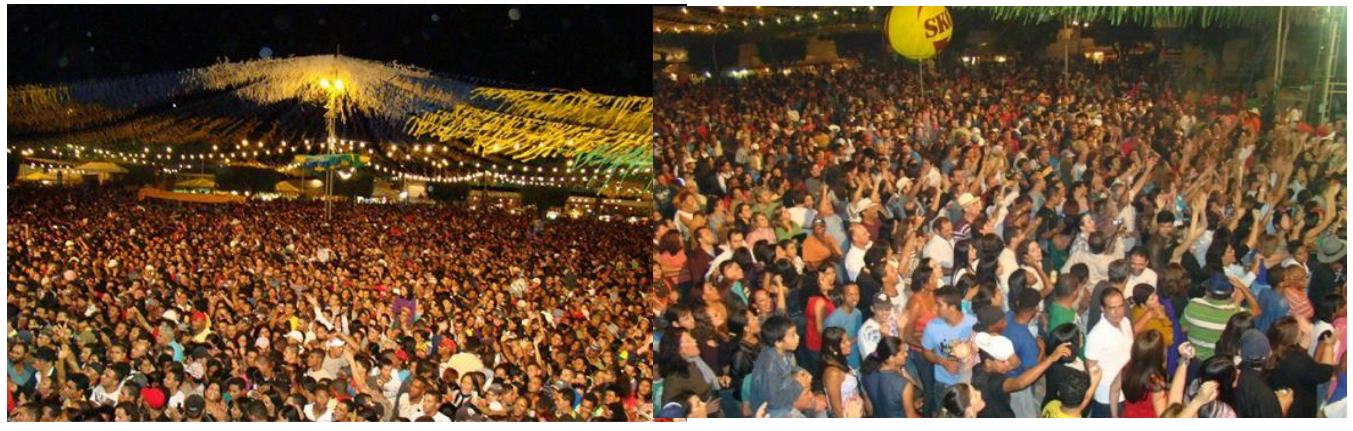

Fotógrafa: Fabiana Nery, pesquisa de campo, 2014.

Além de contratar cantores de fama, os organizadores do evento dão prioridade a bandas locais, que apresentam músicas dedicadas ao homem do 
campo e à representatividade da cultura calmonense. Dessa maneira, pode-se afirmar que o diferencial do São João Calça Curta está em valorizar a comunidade anfitriã e ofertar aos turistas atrativos que os motivem a retornar em todas as edições do evento.

Figura 7. Banda local Luzzo Xodó de Pai e Mr. Maia (2014)
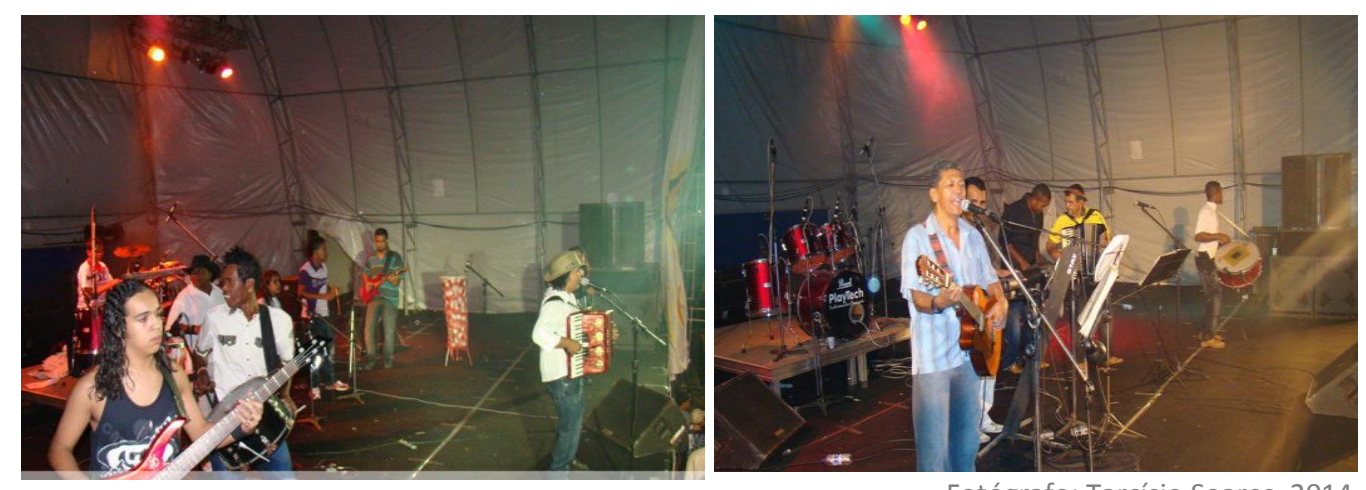

Fotógrafo: Tarcísio Soares, 2014.

Essa banda é formada por integrantes do município de Miguel Calmon e seu principal ritmo é o forró. Ela se apresentou durante a abertura da festa, em 21 de junho e também à tarde, momento em que grupos se reuniram para animar os visitantes que vieram conhecer a localidade. Logo após a apresentação dos artistas, houve a competição do pau de sebo, em que as pessoas sobem e ganha quem conseguir retirar o objeto que está no final da madeira. Esse atrativo é, segundo turistas e organizadores, um dos grandes diferenciais da folia calmonense.

Consideram-se as festividades como recursos em potencial para o turismo, tendo-se em mente que a cultura e as expressões culturais, na pluralidade, são condições essenciais para a existência do turismo em qualquer localidade. Para isso, a participação ativa da comunidade em todo o processo é de extrema importância, pois tem a capacidade de repassar por meio das danças e afins seu modo de viver. O grupo dos caracterizados, por sua vez, vem reforçar essa análise e contribuir para a diversão dos que visitam o município. 


\section{Considerações finais}

O turismo, por ter a capacidade de atrair visitantes de várias partes do mundo e estar altamente inserido nos aspectos sociocultural, econômico e político, pode ser considerado como um instrumento fundamental para o desenvolvimento turístico dos destinos. Além disso, são seus variados segmentos que motivam os turistas a deslocarem-se de suas regiões para conhecer e vivenciar novas culturas (CERQUEIRA, 2008).

Ressalte-se que os eventos e as manifestações culturais, por sua vez, são segmentos do turismo de forte influência no Brasil, em razão da história, tradição e identidade cultural do povo. Dá-se a propagação da atividade turística pelo aumento da procura por atividades culturais e, também, pelas estratégias efetivas de diversificação da oferta nos destinos. Como exemplo, há os festejos juninos, expressão das manifestações culturais, que têm a capacidade de demonstrar, por meio de danças, músicas e comidas típicas, a representatividade da cultura de determinado grupo (CASTRO, 2009).

Durante a pesquisa, pôde-se constatar que o diferencial do São João de Miguel Calmon está na dimensão e na representatividade da cultural local. Assim, pode-se considerar que esse evento apresenta elementos fundamentais para tornar-se um atrativo cultural para o município.

Outro fator de extrema relevância é a inserção da população local, no decorrer do festejo, ao contribuir para a propagação da cultura e a valorização do sentimento de pertencimento da localidade, fator fundamental, uma vez que, com a junção dos aspectos culturais com os atrativos da comunidade, ganha o município maior visibilidade e credibilidade, por meio do aumento de turistas, além do reconhecimento nos âmbitos local e regional (DALLARI, 1993).

Quanto à tradição, os organizadores do evento buscam reforçar, como notado, as características de festejo junino, pela ornamentação do espaço que sedia a festa, pela contratação dos artistas que ali se apresentam e pela inserção 
de outros atrativos, como comidas típicas, casamento caipira, quadrilhas juninas e outras representações culturais, criados por moradores de Miguel Calmon.

Os benefícios da festividade encontram-se na geração de renda, de forma direta e/ou indireta, a todos os citadinos, como o aumento das vendagens na feira livre, no salão de beleza, entre lavadores de carros e no fluxo de pousadas, lanchonetes e restaurantes e outros serviços geradores de postos de trabalho. $\mathrm{O}$ maior recurso gira em torno do local da festa com as concentrações de barracas.

Notou-se que, diferentemente de outros destinos, o São João de Miguel Calmon é intrinsicamente voltado para a tradição e a valorização cultural, o que o mantém como principal atrativo do município.

Por fim, constatou-se, por meio da pesquisa de campo, seguida da análise e das respostas contidas neste trabalho, aliada à conceituação de cultura e seus desdobramentos, que o São João Calça Curta tem potencialidade como produto turístico-cultural para o município de Miguel Calmon Bahia.

\section{Referências}

AMARAL, Rita. Festa à brasileira: sentidos do festejar no país que "não é sério". Disponível em: $<$ http://www.aguaforte.com/antropologia/festaabrasileira/festa.html>. Acesso em: 28 abr. 2014.

ANDRADE, J. V. de. Manual de iniciação ao estudo do turismo. Campinas: Papirus, 1999.

Turismo: fundamentos e dimensões. São Paulo: Ática, 2000.

ARENDT, H. Entre o passado e o futuro. Trad. de Mauro W. Barbosa. São Paulo: Perspectiva, 2002.

BARBOSA, Y. de M. História das viagens e do turismo. São Paulo: Aleph, 2002.

BARRETO, M. Turismo e legado cultural: as possibilidades do planejamento. Campinas: Papirus, 2003.

BARROS, M. O; SILVA, S. C. O desenvolvimento do turismo: uma visão sistêmica. In: CONGRESSO BRASILEIRO DE SISTEMAS, 4., 2008. Anais... Franca-SP: Uni-FACEF, 2008, p.10.

BAKHTIN, M. A cultura popular na Idade Média e no Renascimento: o contexto de François Rabelais. São Paulo/Brasília: Hucitec-UnB, 2008. 
BENI, M. C. Análise estrutural do turismo. 8. ed. atual. São Paulo: Editora SENAC, 2003.

BIGNAMI, R. Comunicação como fator estratégico do produto turístico. In: RUSCHMANN, D. V. M.; SOLHA, K. T. (orgs.) Turismo: uma visão empresarial. Barueri: Manole, 2004.

BOITEUX, B; WERNER, M. Promoção, entretenimento e planejamento turístico. 2. ed. São Paulo: Aleph, 2003.

BOSI, A. Plural, mas não caótico. In: Paulo: Ática, 1999, p. 7-15. . (org.) Cultura brasileira: temas e situações. 4. ed. São

BOULLÓN, R. Projetos turísticos: metodologia para acertar os erros. Buenos Aires: Turísticas, 2002.

CANCLINI, N. G. Culturas híbridas: estratégias para entrar e sair da modernidade. Trad. Heloísa Pezza Cintrão e Ana Regina Lessa. 4. ed. São Paulo: Editora da USP, 2003.

O patrimônio cultural e a construção imaginária nacional. Revista do Patrimônio Histórico e Artístico Nacional. Rio de Janeiro, n. ${ }^{\circ}$ 23, p. 94-115, 1999.

CARVALHO, J. J. O lugar da cultura tradicional na sociedade moderna. In: Seminário folclore e cultura popular: as várias faces de um debate. 2. ed. Rio de Janeiro: Funarte, CNFCP, p. 3864, 2000.

CARVALHO, K. D. Identidade, turismo e tradução cultural: análise da dinâmica dos eventos juninos no Maranhão. Rosa dos Ventos, Caxias do Sul, vol. 3, n. ${ }^{\circ}$ 1, jan./jun. 2011.

CASTRO, J. R. B. de. O papel das manifestações culturais locais/regionais no contexto da turistificação das festas juninas espetacularizadas em Cachoeira-BA. Salvador: FACOM/UFBA, 2009.

. Os festejos juninos na cidade de Amargosa-BA: uma análise da ressignificacão da festa e do fomento. In: ENECULT - Encontro de Estudos Multidisciplinares em Cultura, 3., 23-25 maio 2007, Salvador, Anais... Salvador, FACOM/UFBA.

CERQUEIRA, L. R. O segmento do turismo de negócios e eventos como estratégia competitiva para os destinos turísticos do Brasil: perspectivas e desafios. Belo Horizonte: ANPTUR, 2008.

COOPER, C. et al. Turismo: princípios e práticas. 2. ed. Porto Alegre: Bookman, 2001.

COUTINHO, H, P. M. Turismo de eventos como alternativa para o problema da sazonalidade turística. Revista Eletrônica Aboré (ESAT-UEA), Manaus, mar. 2007.

CRUZ, Mércia Socorro Ribeiro. Festas culturais: tradição, comidas e celebrações. In: EBECULT — Encontro Baiano de Cultura, 1., 11 dez. 2008, Salvador, Anais... Salvador, FACOM/UFBA.

DALLARI, Dalmo de Abreu. O que é participação política?. São Paulo: Brasiliense, 1983 (Col. Primeiros Passos).

DIAGNÓSTICO DO MUNICÍPIO DE MIGUEL CALMON, Bahia, 2009.

DIAS, Reinaldo. Introdução ao turismo. São Paulo: Atlas, 2005. 
FISHER, Fernando. Baixo Sul da Bahia: uma proposta de desenvolvimento territorial. Salvador: CIAGS-UFBA, 2007.

FOSCARINI, A. G. As manifestações culturais populares como atrativos turísticos: estudo de caso do Batuque em Lapinha da Serra-MG. 2009. 88 f. Dissertação (Graduação em ...?) — Universidade Federal de Minas Gerais, Minas Gerais.

FOSTER, G. M. As culturas tradicionais e o impacto da tecnologia. São Paulo: Fundo de Cultura, 1964.

FUNDAÇÃO INSTITUTO BRASILEIRO DE GEOGRAFIA E ESTATÍSTICA - IBGE. Mapas-Base dos municípios do estado do Piauí. Escalas variadas. Inédito. 2009.

GEERTZ, C. A interpretação das culturas. Rio de Janeiro: LTC, 2008.

GOELDNER, Charles R. et al. Turismo: princípios, práticas e filosofias. Porto Alegre-RS: Bookman, 2002.

GOMES, Ângela Araújo. A contribuição dos eventos culturais para a promoção turística de Teresina-Piauí. São Paulo, SP: Universidade Anhembi Morumbi - UAM, 2009.

GUIA LOCAL. Parque Estadual das Sete Passagens. Visita em: 2 jul.2014.

HARVEY, David. A condição pós-moderna. São Paulo: Loyola, 1993.

KOTLER, P. Administração de marketing. São Paulo: Atlas, 1996.

LAKATOS, E. M; MARCONI, M. de. A. Metodologia científica. 4. ed. São Paulo: Atlas, 2004.

MARTIN, Vanessa. Manual prático de eventos. São Paulo: Atlas, 2003.

MATIAS, Marlene. Organização de eventos. 2. ed. Barueri: Manole, 2000.

MELO NETO, F. P. de. Marketing de eventos. 3. ed. Rio de Janeiro: Sprint, 2001.

MENESES, J. N. C. História e turismo cultural. Belo Horizonte: Autêntica, 2004.

MIDDLETON, V. T. C. Marketing de turismo. 2. ed. São Paulo: Roca, 2002.

MONTANER MONTEJANO, Jordi. Estrutura do mercado turístico. Trad. Andréa Favano. São Paulo: Roca, 2001.

NÓBREGA, Zulmira Silva. A festa do maior São João do Mundo: animação para turistas e residentes. Revista Iberoamericana de Turismo - RITUR, Penedo, vol. 2, 2012.

OLIVEIRA, G. C. F de. Carnavalização do São João em Senhor do Bonfim-Bahia: tradição em movimento. Salvador-Bahia: Facom-UFBA, 2010.

PANOSSO NETTO, A.; ANSARAH, M. G. R. (Orgs.) Segmentação do mercado turístico: estudos, produtos e perspectivas. Barueri-SP: Manole, 2009, vol. 1.

PÉREZ, X. P. Turismo cultural: uma visão antropológica. Revista de Turismo y Patrimonio Cultural, Espanha, 2009. 


\section{Fabiana Nery dos Santos}

Grupo de Pesquisa MEL-UNEB

Graduanda no curso de Turismo da Universidade do Estado da Bahia - UNEB - no Departamento de Ciências Humanas e Tecnologias, Campus XVIII

Fabi_nery.geter@hotmail.com

\section{Ana Paula Carvalho Cruz Feitosa}

Doutora em Artes Cênicas pela UNEB (2005)

Professora auxiliar do Curso de Bacharelado em Turismo, Campus XVIII, Eunápolis-BA

donanafeitosa@hotmail.com

Bairro Santa Lúcia- Norte Sul- Eunápolis 